\title{
Acupuncture for the Treatment of Peripheral Neuropathy: A Systematic Review and Meta-Analysis
}

\author{
Alexandra Dimitrova, MD, Charles Murchison, MS, and Barry Oken, MD, PhD
}

\begin{abstract}
Objectives: Neuropathy and its associated pain pose great therapeutic challenges. While there has been a recent surge in acupuncture use and research, little remains known about its effects on nerve function. This review aims to assess the efficacy of acupuncture in the treatment of neuropathy of various etiologies.

Methods: The Medline, AMED, Cochrane, Scopus, CINAHL, and clintrials.gov databases were systematically searched from inception to July 2015. Randomized controlled trials (RCTs) assessing acupuncture's efficacy for poly- and mononeuropathy were reviewed. Parallel and crossover RCTs focused on acupuncture's efficacy were reviewed and screened for eligibility. The Scale for Assessing Scientific Quality of Investigations in Complementary and Alternative Medicine was used to assess RCT quality. RCTs with score of $>9$ and active control treatments such as sham acupuncture or medical therapy were included.

Results: Fifteen studies were included: 13 original RCTs, a long-term follow-up, and a re-analysis of a prior RCT. The selected RCTs studied acupuncture for neuropathy caused by diabetes, Bell's palsy, carpal tunnel syndrome, human immunodeficiency virus (HIV), and idiopathic conditions. Acupuncture regimens, control conditions, and outcome measures differed among studies, and various methodological issues were identified. Still, the majority of RCTs showed benefit for acupuncture over control in the treatment of diabetic neuropathy, Bell's palsy, and carpal tunnel syndrome. Acupuncture is probably effective in the treatment of HIV-related neuropathy, and there is insufficient evidence for its benefits in idiopathic neuropathy. Acupuncture appears to improve nerve conduction study parameters in both sensory and motor nerves. Meta-analyses were conducted on all diabetic neuropathy and Bell's palsy individual subject data (six RCTs; a total of 680 subjects) using a summary estimate random effects model, which showed combined odds ratio of 4.23 (95\% confidence interval 2.3-7.8; $p<0.001$ ) favoring acupuncture over control for neuropathic symptoms.

Conclusions: Acupuncture is beneficial in some peripheral neuropathies, but more rigorously designed studies using sham-acupuncture control are needed to characterize its effect and optimal use better.
\end{abstract}

Keywords: neuropathic pain, neuropathy, acupuncture, integrative medicine

\section{Introduction}

A CUPUNCTURE HAS RECENTLY EMERGED as an important integrative medicine treatment, in both the hospital and clinic settings. ${ }^{1,2}$ In 1998, an National Institutes of Health Consensus Development Panel concluded that acupuncture is efficacious for postoperative and chemotherapy-induced nausea and vomiting, and helpful in other conditions, including stroke rehabilitation. ${ }^{3}$ Newer evidence-based reviews have shown the therapeutic benefits of acupuncture for chronic lowback pain, ${ }^{4,5}$ migraine and tension headache, ${ }^{6,7}$ chemotherapyinduced nausea and vomiting, ${ }^{8}$ and other pain conditions. ${ }^{9}$
Peripheral neuropathy (PN) is broadly defined as damage to the peripheral nervous system caused by a primary lesion or dysfunction, ${ }^{10}$ with polyneuropathy involving multiple nerves and mononeuropathy involving a single nerve. The most common causes of polyneuropathy are diabetes, thyroid disorders, vitamin B12 deficiency, alcohol abuse, chemotherapy, and human immunodeficiency virus (HIV) infection. ${ }^{10,11}$ In spite of exhaustive workups, no cause is identified in one third of PN cases, and they are considered idiopathic. ${ }^{11,12}$ The most common mononeuropathies are carpal tunnel syndrome (CTS), which is caused by demyelination of the median nerve at the wrist, ${ }^{10}$ and Bell's palsy, which involves the facial nerve and

Department of Neurology, Oregon Health and Science University, Portland, OR. 
causes facial weakness. ${ }^{13} \mathrm{PN}$ is often accompanied by painful paresthesias, which present a great therapeutic challenge. ${ }^{10,14}$ Integrative treatments such as acupuncture are used in pain clinics with increasing popularity and are gaining acceptance among the U.S. public and academic community. ${ }^{15,16}$ This acceptance of acupuncture has prompted growing research into integrative therapies for the challenging treatment of neuropathic pain. To the authors' knowledge, there has been no critical, systematic appraisal of the effects of acupuncture across all types of neuropathy, including both poly- and mononeuropathy.

\section{Objectives}

The objective of this review is to examine critically the evidence in the published literature for the safety and efficacy of acupuncture in the treatment of PN and associated symptoms compared to sham acupuncture or conventional medical therapy. Furthermore, acupuncture's effectiveness across various neuropathic conditions, as evidence permits, is also assessed.

\section{Methods}

\section{Search strategy}

The following electronic databases were searched from inception to July 2015: Medline, Cochrane Library, Scopus, AMED, CINAHL, and Clintrials.gov. The key search terms used were (["acupuncture" OR "acup*" OR "laser acupuncture" OR "moxibustion" OR "electroacupuncture"] AND ["neuropathy" OR "peripheral neuropathy" OR "neuropathic pain" OR "neuralgia" OR "carpal tunnel syndrome" OR "Bell's palsy"]). Review papers were used to identify additional references. Language restrictions were set to English and subject restrictions to humans. Gray literature in clintrials.gov was reviewed for unpublished relevant data. Parallel and crossover RCTs were selected if their focus was acupuncture as an intervention for the treatment of PN, regardless of blinding. RCTs were selected if they included at least one group receiving acupuncture and one control group receiving sham acupuncture or another active treatment (e.g., medication).

\section{Subject characteristics}

Only adults (age $>18$ years) were included in the search parameters, as neuropathy, with the exception of Bell's palsy and hereditary neuropathies, is rare in children. The type of PN studied was further stratified by etiology as diabetic, chemotherapy-induced, HIV-induced, post-herpetic, idiopathic, or mononeuropathy such as CTS or Bell's palsy.

\section{Intervention}

Acupuncture was defined as the stimulation of acupuncture points by needles that pierce the skin, with or without electric stimulation, with or without moxibustion (heating with the mugwort herb). Methods of stimulating acupuncture points without needle insertion (laser, acupressure) were also searched. Controls needed to be active and included sham acupuncture or relevant medical treatments such as drugs or injections. Co-interventions were allowed only if they were given to both the intervention and the control group.

\section{Outcome measures}

One of the following outcome measures was required for inclusion: nerve conduction studies (NCS); validated questionnaires such as Symptom Severity Score, the Visual Analogue Scale, Global Symptom Score, or McGill Pain Questionnaire score; or clearly defined study-specific objective criteria distinguishing responders from nonresponders.

\section{Data extraction}

The review team consisted of two neurologists with expertise in acupuncture, neuromuscular disorders, neurophysiology, and statistical methodology. Initially, an abstract review was performed to determine study eligibility. Studies were excluded if they were not RCTs or did not have acupuncture or PN as their focus. Other reasons for exclusion were the lack of a non-acupuncture control condition, such as comparing acupuncture with manual manipulation to acupuncture without manual manipulation or comparing acupuncture plus moxibustion to acupuncture alone. The remaining studies were reviewed in detail.

The Scale for Assessing Scientific Quality of Investigations in Complementary and Alternative Medicine Version (SASQI CAM), an instrument specifically designed to evaluate RCTs focused on integrative therapies, ${ }^{17}$ was utilized. It assesses methodological problems and sources of bias commonly encountered in integrative medicine research, such as allocation concealment, investigator and subject blinding, blinded outcome assessment, reproducibility of experimental procedures, and sound statistical analysis. The two reviewers assigned each paper a SAS-QI CAM score independently and in a blinded fashion. As the two reviewers were in agreement, there was no need to use a third reviewed as tiebreaker. Based on a recent study by D'Silva et al., ${ }^{18}$ a SAS-QI CAM score of $>9$ (out of 21) served as the cutoff for inclusion based on RCT overall scientific quality.

\section{Data synthesis plan}

All included RCTs on acupuncture for diabetic peripheral neuropathy (DPN) and Bell's palsy used composite improvement scales such as "markedly relieved/improved/failed" 19 or "marked effectiveness/effectiveness/failure," ${ }^{20}$ reported at the level of the individual subject. These were converted to dichotomous "no improvement" and "improvement" variables and included in meta-analysis using standard pooling procedures based on odds ratios. Contingency tables were developed with acupuncture as the treatment marginal and improvement from baseline as the outcome marginal. Fisher's exact test was used to calculate the odds ratios as the primary endpoints. Weights for the studies were calculated based on reciprocal of the variance and normalized based on the total sum of the weights used in the meta-analyses. In addition to a standard fixed-effects Mantel-Haenszel model, a random effects metaanalysis was done due to the expected increase in heterogeneity resulting from combining Bell's palsy and DPN studies. Beyond the basal evaluation, a separate meta-analysis was conducted exclusively on the DPN subjects. All statistical analyses were conducted using $\mathrm{R} v 3.0 .2^{21}$ with additional utility from the "rmeta" package. ${ }^{22}$ 
Results

\section{Included studies}

Initial searches generated 1008 records, and 772 remained after duplicate removal (Fig. 1). Of these, 726 studies were excluded after abstract review, leaving 46 to be reviewed in detail for eligibility. Initial searches identified studies with a focus on acupuncture for the treatment of DPN, chemotherapy-induced neuropathy, HIV-related neuropathy, idiopathic neuropathy, zoster neuralgia, traumatic peroneal neuropathy, and various cranial neuropathies such as Bell's palsy and trigeminal neuralgia. Of the 46 studies that underwent full review, 15 were excluded because they were not RCTs ${ }^{23-37}$ : three for an improper control condition, including verum acupuncture ${ }^{38-40}$; three because they did not focus on acupuncture/involved multiple interventions ${ }^{41-43}$; one ${ }^{44}$ because it was identified as a duplicate to an included paper ${ }^{45}$; one because it was descriptive only ${ }^{46}$; and eight because of a low SAS-QI CAM score $(<10){ }^{4}$

Following a detailed review, 15 papers met the final inclusion criteria (Table 1): 13 RCTs, a 13-month follow-up ${ }^{55}$ of an original RCT, ${ }^{56}$ and a re-analysis ${ }^{57}$ of a previously published paper. ${ }^{58}$ The selected studies focus on acupuncture for the treatment of neuropathy caused by Bell's palsy, ${ }^{45,59}$ CTS, ${ }^{55,56,60-62}$ diabetes, ${ }^{19,20,63,64}$ HIV ${ }^{57,58,65}$ and a combination of diabetes and idiopathic causes. ${ }^{66}$ Of the included RCTs, nine studied manual acupuncture with or without moxibustion, three studied electroacupuncture, and one studied a combination of manual and electroacupuncture. Other active interventions included per os (P.O.) medications, intramuscular (i.m.)/intravenous (i.v.) injections, or splinting. As planned, all selected studies had an active control arm.

All included RCTs studied adult male and female outpatients, with the exception of $\mathrm{Yu}$ et al. who studied diabetic neuropathy in the hospital setting ${ }^{19}$ (Table 2). While most studies originated in China, ${ }^{19,20,45,56,59,63,64}$ others involved outpatients in Iran, ${ }^{60}$ Thailand, ${ }^{61}$ and the United States. ${ }^{58,62,65,66}$ Across studies, sample sizes ranged from 16 to 480 subjects, treatment courses ranged from 20 days to 3 months, and acupuncture frequency ranged from daily to weekly. There was significant variability in how neuropathy was diagnosed, including neurologic exam, symptom scales, NCS, and serologic testing. The same applied to outcome measures, which ranged from subjects' symptom ratings to validated clinical scales (Table 3), NCS (Table 4), serologic testing, and study-specific graded improvement scales.

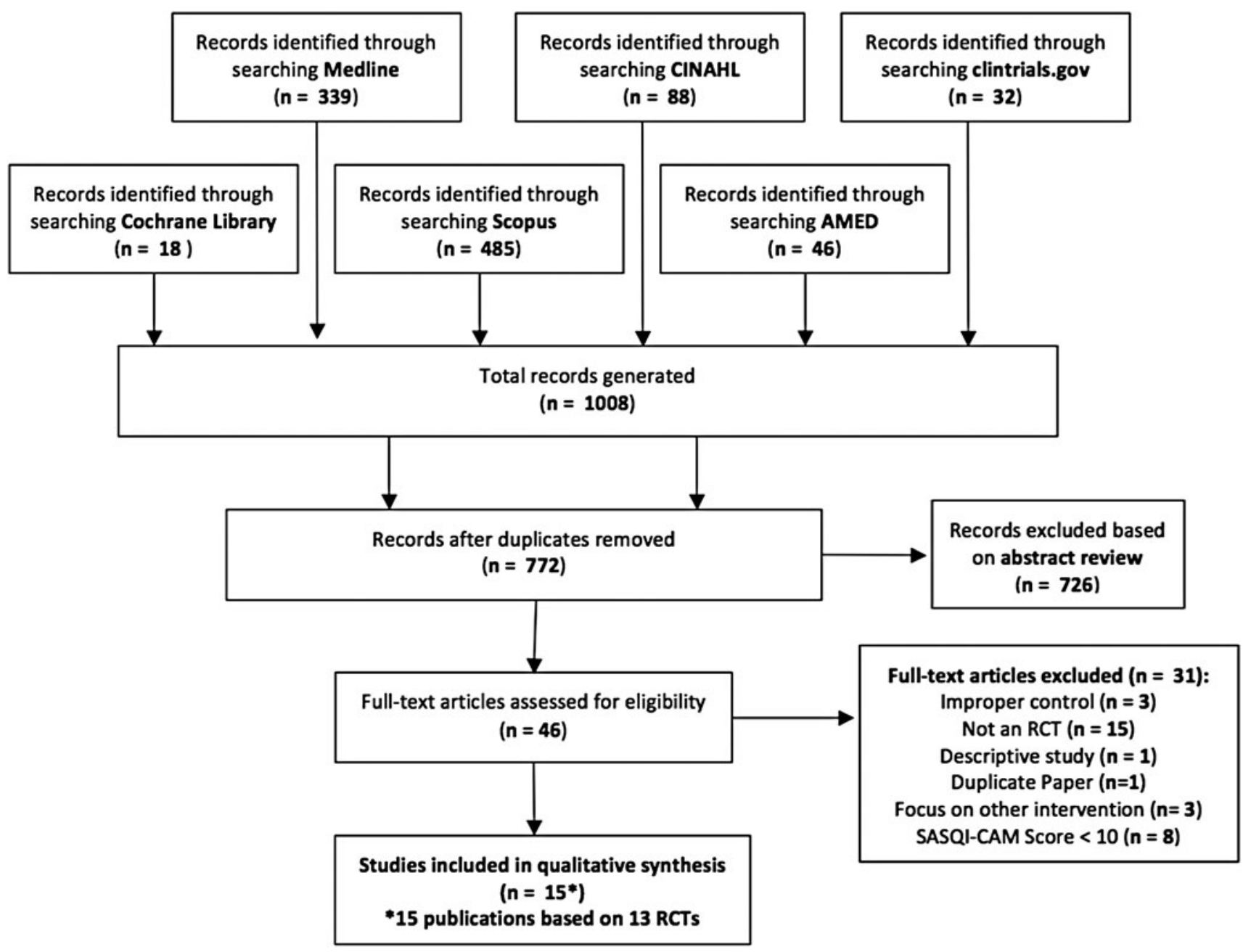

FIG. 1. Database search flow diagram. 
Table 1. Study Quality Ratings Using the Scale for Assessing Scientific Quality of Investigations in Complementary and Alternative Medicine

\begin{tabular}{|c|c|c|c|c|}
\hline Study & Condition & SASQI-CAM & Intervention & Control \\
\hline Li et al., $2004^{45}$ & Bell's palsy & $13 / 21$ & Acupuncture, moxibustion & $\begin{array}{l}\text { 1. Acupuncture, moxibustion, } \\
\text { meds P.O. and i.m. } \\
\text { 2. Meds P.O. and i.m. }\end{array}$ \\
\hline Tong et al., $2009^{59}$ & Bell's palsy & $14 / 21$ & Acupuncture & $\begin{array}{l}\text { 1. Prednisolone P.O. + } \\
\text { pepcidine P.O. }{ }^{\text {a }} \\
\text { 2. Conservative Tx } \\
\text { (non-medical) }\end{array}$ \\
\hline Khosrawi et al., $2012^{60}$ & CTS & $19 / 21$ & Acupuncture, splinting & $\begin{array}{l}\text { Sham acupuncture, splinting, } \\
\text { Vitamins B1 and B6 P.O. }\end{array}$ \\
\hline Kumnerddee et al., $2010^{61}$ & CTS & $14 / 21$ & Electroacupuncture & Splinting \\
\hline Yao et al., $2012^{62}$ & CTS & $17 / 21$ & Acupuncture, splinting & Sham acupuncture, splinting \\
\hline Yang et al., $2009,{ }^{56} 2011^{55}$ & CTS & $18 / 21$ & Acupuncture & Prednisolone P.O. \\
\hline Yu et al., $2001^{19}$ & $\mathrm{DM}$ & $10 / 21$ & Electroacupuncture & Meds P.O. and i.m. \\
\hline Zhang et al., $2010^{63}$ & $\mathrm{DM}$ & $11 / 21$ & Acupuncture & Inositol P.O. \\
\hline Zheng et al., $2004^{64}$ & $\mathrm{DM}$ & $10 / 21$ & $\begin{array}{l}\text { Acupuncture, electroacupuncture, } \\
\text { snow lotus i.m. injection }\end{array}$ & Mecobalamin P.O. \\
\hline Zuo et al., $2010^{20}$ & DM & $12 / 21$ & Acupuncture, vitamin B12 i.v. & Vitamin B12 i.v. \\
\hline Anastazi et al., $2013^{65}$ & HIV & $18 / 21$ & Acupuncture, moxibustion & $\begin{array}{l}\text { Sham acupuncture, placebo } \\
\text { moxibustion }\end{array}$ \\
\hline Schiflett et al., $2011^{57}$ & HIV & $15 / 21$ & Acupuncture & $\begin{array}{l}\text { Control (non-acupuncture) } \\
\text { points }\end{array}$ \\
\hline Shlay et al., $1998^{58}$ & HIV & $19 / 21$ & $\begin{array}{l}\text { 1. Acupuncture } \\
\text { 2. Acupuncture, amitriptyline } \\
\text { 3. Acupuncture, placebo P.O. }\end{array}$ & $\begin{array}{l}\text { 1. Control (non-acupuncture) } \\
\text { points } \\
\text { 2. Control points, } \\
\text { amitriptyline } \\
\text { 3. Control points, placebo } \\
\text { P.O. } \\
\text { 4. Amitriptyline } \\
\text { 5. Placebo P.O. }\end{array}$ \\
\hline Penza et al., $2011^{66}$ & DM/IPN & $12 / 21$ & Electroacupuncture & Sham electroacupuncture \\
\hline
\end{tabular}

${ }^{\mathrm{a}}$ Control condition included in meta-analysis.

CTS, carpal tunnel syndrome; DM, diabetes mellitus; i.m., intramuscular; P.O., per os (oral); HIV, human immunodeficiency virus; i.v., intravenous; IPN, idiopathic peripheral neuropathy; Tx, treatment; SASQI-CAM, scale for assessing scientific quality of investigations in complementary and alternative medicine.

\section{$D P N$}

Four RCTs met the eligibility criteria. ${ }^{19,20,63,64}$ These studies were conducted in China and used manual acupuncture ${ }^{20,63,64}$ or electroacupuncture ${ }^{19,64}$ in combination with snow lotus injection in acupuncture points ${ }^{64}$ and i.v. vitamin B12. ${ }^{20}$ All studies used P.O., i.m., or i.v. medication control (Table 2). Outcome measures included study-specific graded composite improvement scales based on symptoms, ${ }^{19,20,63,64}$ clinical signs, ${ }^{63}$ exam, ${ }^{19,63}$ labs, ${ }^{19}$ and NCS. ${ }^{19,20}$ The included studies reported significant improvement in acupuncture groups compared with control in neurologic exam, ${ }^{19,20,64}$ neuropathic symptoms, ${ }^{19,63,64}$ composite improvement scales, ${ }^{19,20,63,64}$ NCS, ${ }^{19,20}$ and blood rheology. ${ }^{19}$

\section{HIV-related neuropathy}

One included study of manual acupuncture for HIV-related neuropathy from the early-mid $1990 \mathrm{~s}^{58}$ had enrollment difficulties and a $20-35 \%$ dropout rate due to significant HIV morbidity. This led to a complicated "factorial option" design with eight trial arms, which made a direct comparison of amitriptyline to acupuncture impossible. The study found significantly higher pain relief in the acupuncture group $(p=0.03)$. However, this was not true after adjustment for multiple comparisons. Shiflett et al. ${ }^{57}$ reanalyzed data from this trial using baseline pain as a covariate in a repeatedmeasures analysis of covariance and found that baseline pain intensity was significant $(p<0.001)$ and so was the interaction of acupuncture and amitriptyline over time $(p<0.017)$. Amitriptyline alone or acupuncture alone showed significant reduction in Gracely Pain Scale score at 6 weeks. However, only acupuncture sustained this effect at 14 weeks (Tables 2 and 3). When amitriptyline and acupuncture were combined, they did not differ from placebo.

Anastasi et al. ${ }^{65}$ also found significant reduction in Gracely Pain Scale following a 6-week course of manual acupuncture/ moxibustion compared to sham acupuncture/placebo moxibustion control (Table 2). Additionally, the acupuncture group had significant improvement on the Subjective Peripheral Neuropathy Screen compared to its pretreatment baseline.

\section{Idiopathic neuropathy}

One RCT on electroacupuncture for idiopathic neuropathy was included. ${ }^{66}$ Four subjects with diabetic neuropathy and 12 with idiopathic neuropathy were enrolled in a double-blind crossover study comparing electroacupuncture to sham- 


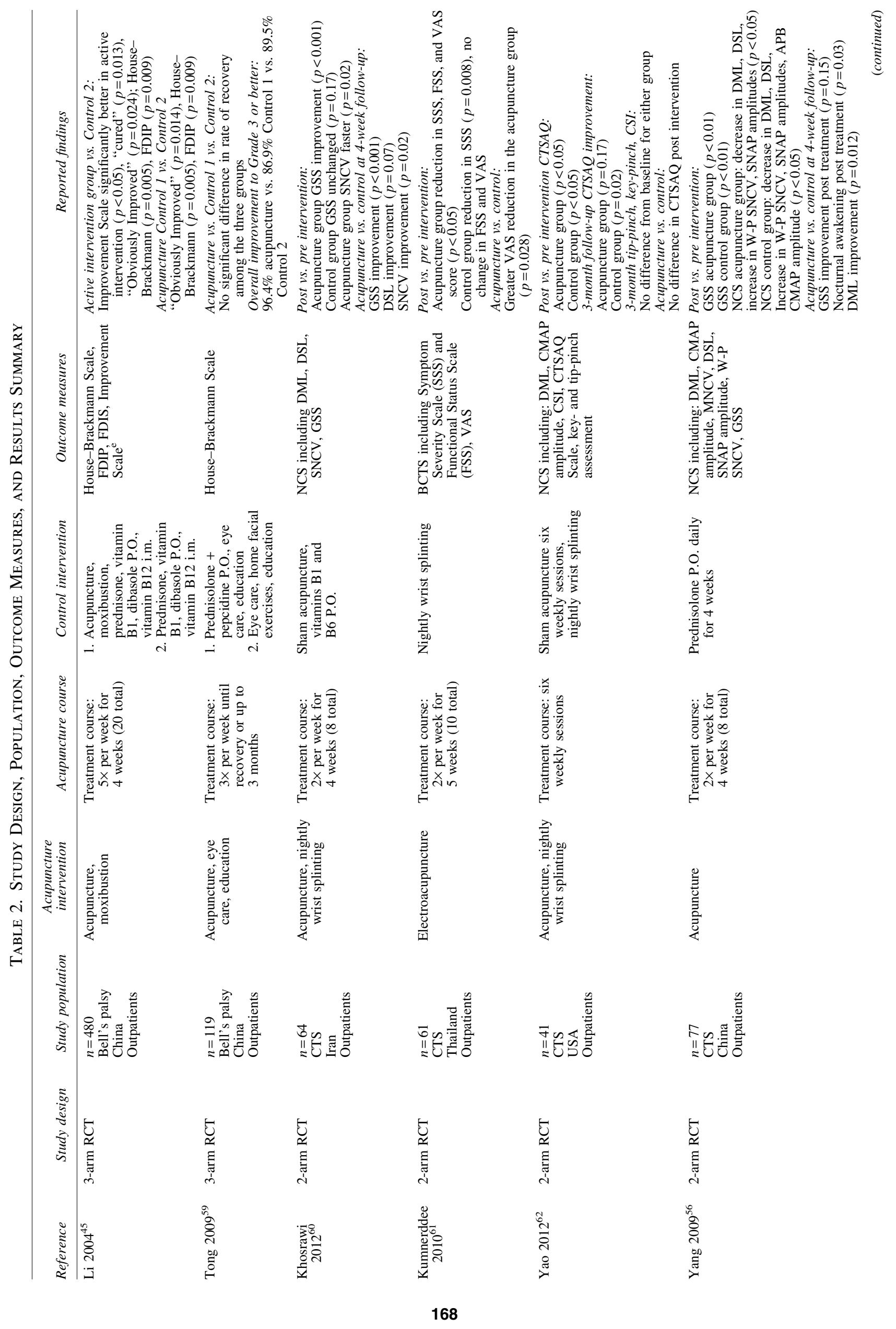




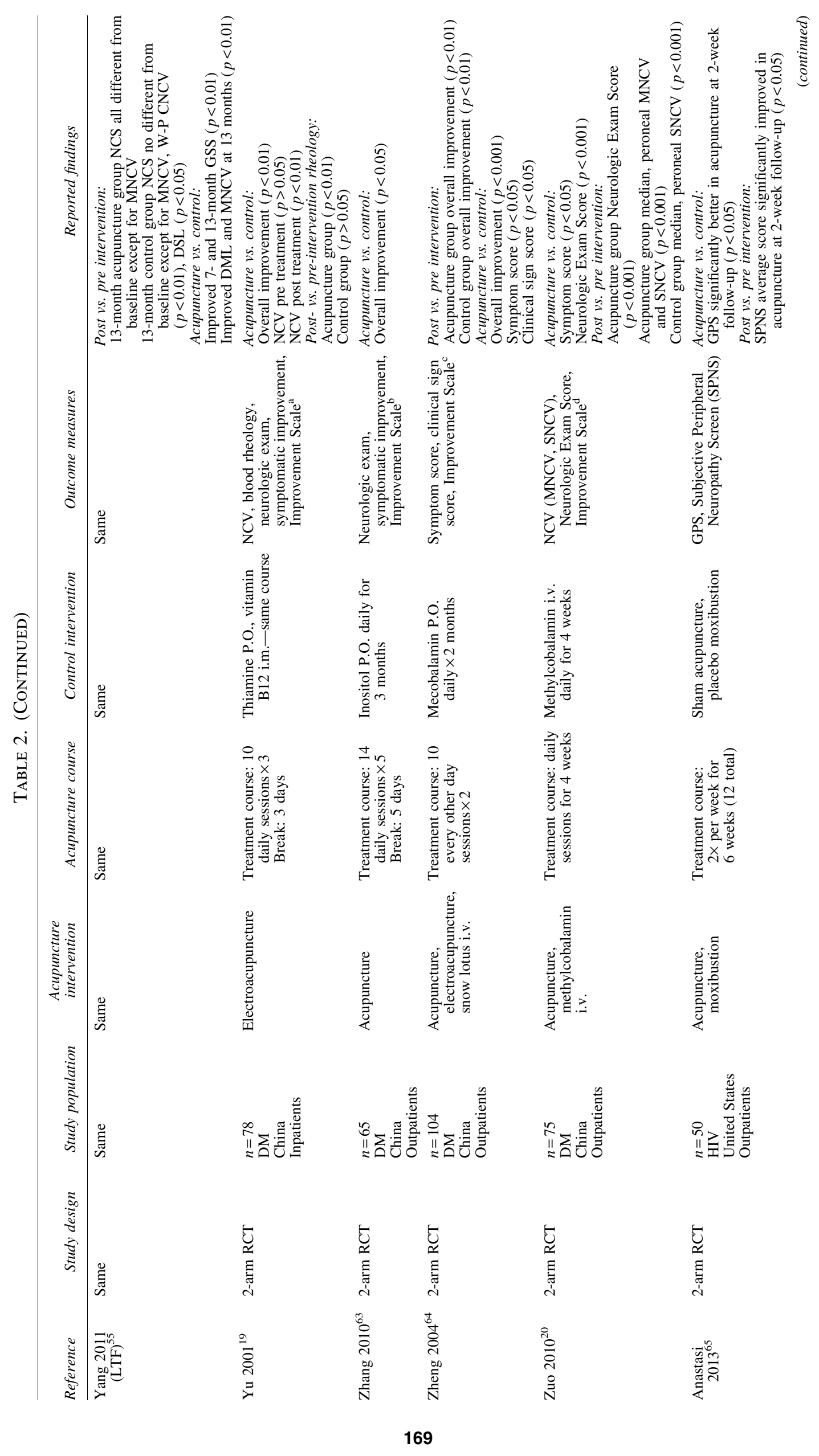




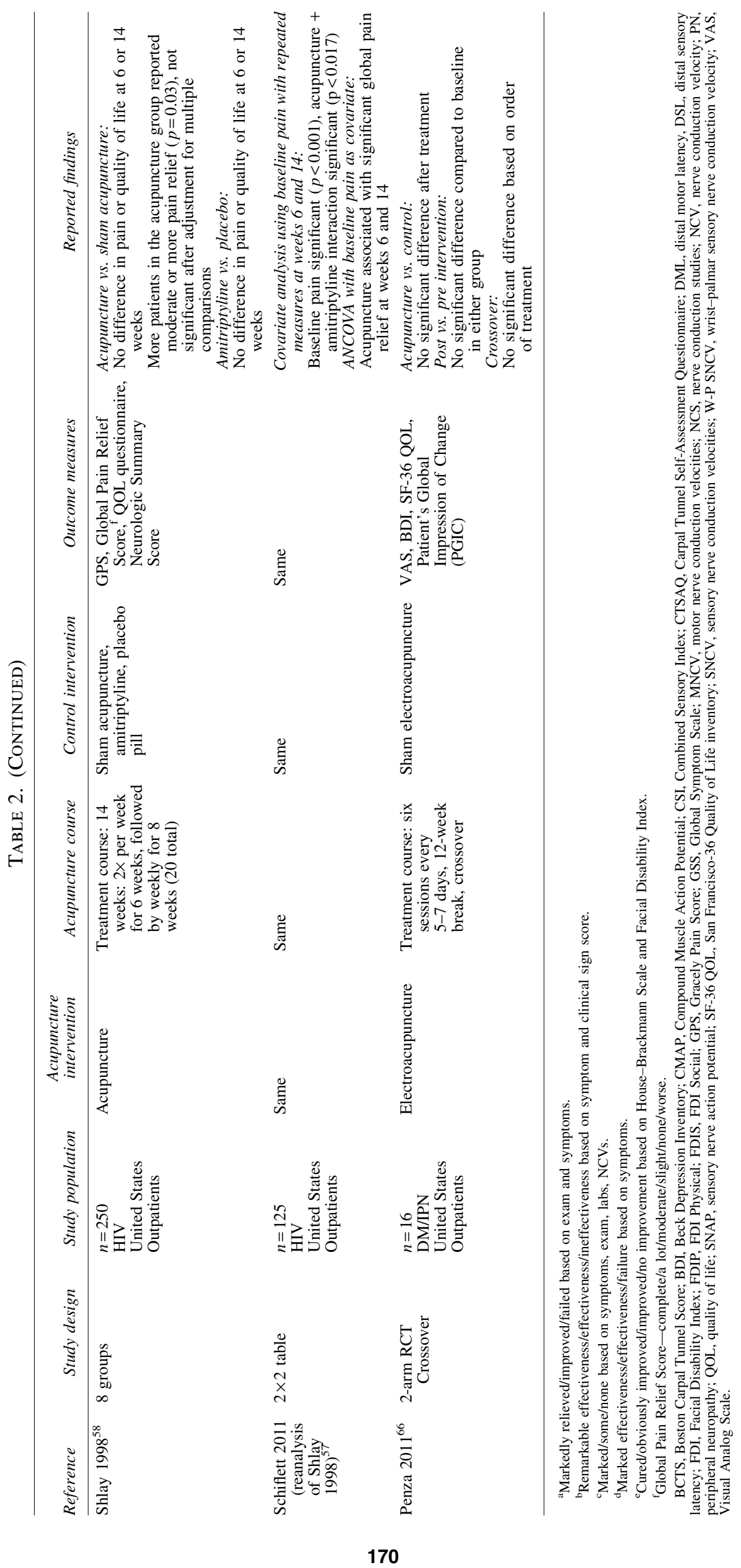


Table 3. Overview of Clinical Scales Used as Outcome Measures

\begin{tabular}{|c|c|c|c|}
\hline Validated scale used & $\begin{array}{l}\text { Neuropathy- } \\
\quad \text { related } \\
\text { condition }\end{array}$ & Study/condition & $\begin{array}{l}\text { Post-acupuncture changes } \\
\text { compared to baseline }\end{array}$ \\
\hline BCTS including Symptom Severity & CTS & Kumnerddee $2010^{61}$ & $\begin{array}{l}\text { Improvement in SSS, FSS at } 5 \text { weeks } \\
(p<0.05)\end{array}$ \\
\hline $\begin{array}{l}\text { Scale (SSS) and Functional Status } \\
\text { Scale (FSS) }\end{array}$ & & & \\
\hline $\begin{array}{l}\text { Carpal Tunnel Self-Assessment } \\
\text { Questionnaire (CTSAQ) }\end{array}$ & CTS & Yao $2012^{62}$ & $\begin{array}{l}\text { Improved post acupuncture }(p<0.05) \\
\text { No difference from baseline at } 3 \text { months }\end{array}$ \\
\hline Global Symptom Score (GSS) & CTS & $\begin{array}{l}\text { Yang } 2009^{56} \\
\text { Yang } 2011^{55} \\
\text { Khosrawi } 2012^{60}\end{array}$ & $\begin{array}{l}\text { Improved at } 4 \text { weeks }(p<0.01) \\
\text { Improved at } 7 \text { and } 13 \text { months }(p<0.01) \\
\text { Improved at } 4 \text { weeks }(p<0.001)\end{array}$ \\
\hline Facial Disability Index (FDIP, FDIS) & Bell’s palsy & $\mathrm{Li} 2004^{45}$ & $\begin{array}{l}\text { Improved FDIP compared to control } \\
\text { at } 4 \text { weeks }(p=0.009)\end{array}$ \\
\hline House-Brackmann Scale & Bell’s palsy & Li 2004 & $\begin{array}{l}\text { Improved over medication control } \\
(p=0.005)\end{array}$ \\
\hline Gracely Pain Scale (GPS) & $\begin{array}{l}\text { HIV } \\
\text { HIV } \\
\text { HIV }\end{array}$ & $\begin{array}{l}\text { Tong } 2009^{59} \\
\text { Anastasi } 2013^{65} \\
\text { Schiflett } 2011^{57} \\
\text { Shlav } 1998^{58}\end{array}$ & $\begin{array}{l}96.4 \% \text { improvement to grade } 3 \text { or better } \\
\text { Improved at } 2 \text {-week follow-up }(p<0.05) \\
\text { N/A }\end{array}$ \\
\hline Karnofsky Score & $\begin{array}{l}\text { HIV } \\
\text { HIV }\end{array}$ & $\begin{array}{l}\text { Schiflett } 2011 \\
\text { Shlay } 1998\end{array}$ & $\begin{array}{l}\text { No difference at } 6 \text { or } 14 \text { weeks } \\
\text { No difference at } 6 \text { or } 14 \text { weeks }\end{array}$ \\
\hline Subjective Peripheral Neuropathy & HIV & Anastasi 2013 & $\begin{array}{l}\text { Average score improved at } 2 \text { weeks } \\
(p<0.05)\end{array}$ \\
\hline $\begin{array}{l}\text { Screen (SPNS) } \\
\text { Visual Analog Scale (VAS) }\end{array}$ & $\begin{array}{l}\text { HIV, DM, } \\
\text { IPN }\end{array}$ & $\begin{array}{l}\text { Kumnerddee } 2010 \\
\text { Penza } 2011^{66}\end{array}$ & Improved at 5 weeks $(p<0.05)$ \\
\hline Beck Depression Inventory & $\mathrm{DM} / \mathrm{IPN}$ & Penza 2011 & No difference after six treatments \\
\hline SF-36 QOL & DM/IPN & Penza 2011 & No difference after six treatments \\
\hline
\end{tabular}

Table 4. Nerve Conduction Study Changes in Acupuncture and Control Groups

\begin{tabular}{|c|c|c|c|}
\hline Nerve conduction study parameter & $\begin{array}{l}\text { Change from baseline } \\
\text { in acupuncture group }\end{array}$ & $\begin{array}{l}\text { Change from baseline } \\
\text { in control group }\end{array}$ & $\begin{array}{c}\text { Change in acupuncture } \\
\text { vs. control }\end{array}$ \\
\hline \multicolumn{4}{|l|}{ Motor NCS } \\
\hline \multicolumn{4}{|c|}{ Compound muscle action potential (CMAP) amplitude } \\
\hline \multirow{2}{*}{ Median nerve } & $\Leftrightarrow$ Yang $2009^{56}$ & $\uparrow$ Yang 2009 & $\Leftrightarrow$ Yang 2009 \\
\hline & \multicolumn{3}{|c|}{ Distal motor latency $(D M L)$} \\
\hline \multirow[t]{3}{*}{ Median nerve } & $\Leftrightarrow$ Khosrawi $2012^{60}$ & $\Leftrightarrow$ Khosrawi 2012 & $\Leftrightarrow$ Khosrawi 2012 \\
\hline & $\downarrow$ Yang 2009 & $\downarrow$ Yang 2009 & $\downarrow$ Yang 2009 \\
\hline & $\Downarrow \Downarrow$ Yang 2011 & $\Leftrightarrow$ Yang 2011 & $\Downarrow \Downarrow$ Yang 2011 \\
\hline \multicolumn{4}{|c|}{ nduction velocity (MNCV) } \\
\hline Ulnar, tibial nerve & $\Uparrow \Uparrow \mathrm{Yu} 2001^{19}$ & $\Leftrightarrow \mathrm{Yu} 2001$ & $\Uparrow \Uparrow \mathrm{Yu} 2001$ \\
\hline \multirow[t]{4}{*}{ Median nerve } & $\Leftrightarrow$ Yang 2009 & $\Leftrightarrow$ Yang 2009 & $\Leftrightarrow$ Yang 2009 \\
\hline & $\Leftrightarrow$ Yang 2011 & $\Uparrow \Uparrow$ Yang 2011 & $\Uparrow \Uparrow$ Yang 2011 \\
\hline & $\Uparrow \Uparrow Y u 2001$ & $\Uparrow \Uparrow \mathrm{Yu} 2001$ & $\Uparrow \Uparrow \mathrm{Yu}_{2} 2001$ \\
\hline & $\Uparrow \Uparrow$ Zuo $2010^{20}$ & $\Leftrightarrow$ Zuo 2010 & $\uparrow$ Zuo 2010 \\
\hline Peroneal nerve & $\Uparrow \Uparrow \mathrm{Zuo} 2010$ & $\Leftrightarrow$ Zuo 2010 & $\uparrow$ Zuo 2010 \\
\hline \multicolumn{4}{|l|}{ Sensory NCS } \\
\hline \multirow{2}{*}{ Median nerve } & $\uparrow$ Yang 2009 & $\uparrow$ Yang 2009 & $\Leftrightarrow$ Yang 2009 \\
\hline & $\Uparrow \Uparrow$ Yang 2011 & $\Uparrow \Uparrow$ Yang 2011 & $\Leftrightarrow$ Yang 2011 \\
\hline \multirow{3}{*}{$\begin{array}{l}\text { Distal sensory latency (DSL) } \\
\text { Median nerve }\end{array}$} & $\Leftrightarrow$ Khosrawi 2012 & $\Leftrightarrow$ Khosrawi 2012 & $\Leftrightarrow(p=0.07)$ Khosrawi 2012 \\
\hline & $\downarrow$ Yang 2009 & $\downarrow$ Yang 2009 & $\Leftrightarrow$ Yang 2009 \\
\hline & $\Downarrow \Downarrow$ Yang 2011 & $\downarrow$ Yang 2011 & $\Leftrightarrow$ Yang 2011 \\
\hline \multicolumn{4}{|c|}{ Sensory nerve conduction velocity (SNCV) } \\
\hline \multirow[t]{4}{*}{ Median nerve } & $\uparrow$ Khosrawi 2012 & $\Leftrightarrow$ Khosrawi 2012 & $\uparrow$ Khosrawi 2012 \\
\hline & $\uparrow$ Yang 2009 & $\uparrow$ Yang 2009 & $\Leftrightarrow$ Yang 2009 \\
\hline & $\Uparrow \Uparrow$ Yang 2011 & $\Leftrightarrow$ Yang 2011 & $\Leftrightarrow$ Yang 2011 \\
\hline & $\Uparrow \Uparrow \mathrm{Zuo} 2010$ & $\Uparrow \Uparrow \mathrm{Zuo} 2010$ & $\Leftrightarrow$ Zuo 2010 \\
\hline Peroneal nerve & $\Uparrow \Uparrow \mathrm{Zuo} 2010$ & $\Uparrow \Uparrow \mathrm{Zuo} 2010$ & $\Leftrightarrow$ Zuo 2010 \\
\hline
\end{tabular}

$\Uparrow \Uparrow$, increased $(p<0.01) ; \uparrow$, increased $(p<0.05) ; \Leftrightarrow$, no significant change $(p>0.05) ; \downarrow$, decreased $(p<0.05) ; \Downarrow \Downarrow$, decreased $(p<0.01)$. 
electroacupuncture (eight subjects per group). There was no difference between acupuncture and control in any of the outcome measures used: Visual Analogue Scale, Patient's Global Impression of Change, Beck Depression Inventory, and the SF-36 Quality of Life Instrument (Table 3). Both groups showed no difference from baseline. The authors did not analyze data from the diabetic and idiopathic neuropathy subjects separately (Table 2).

\section{CTS}

All four RCTs ${ }^{56,60,61,62}$ used validated CTS-specific scales (Table 2) and reported significant improvement with manual acupuncture $^{56,60,62}$ and electroacupuncture ${ }^{61}$ compared with baseline in the Global Symptom Score, ${ }^{56,60}$ Boston Carpal Tunnel Score, ${ }^{61}$ Carpal Tunnel Self-assessment Questionnaire, ${ }^{62}$ and Visual Analogue Scale ${ }^{61}$ (Table 3). Three of the four RCTs included showed significantly greater effectiveness of acupuncture compared with night splinting, ${ }^{61}$ sham acupuncture, ${ }^{60}$ oral vitamin $\mathrm{B} 1$ and $\mathrm{B} 6,{ }^{60}$ and oral prednisolone. ${ }^{56}$ In contrast, Yao et al. ${ }^{62}$ revealed no difference in CTS symptoms between acupuncture plus night splinting compared to sham acupuncture plus night splinting, with both groups improved from baseline. Most long-term follow-ups favored acupuncture at 4 weeks, ${ }^{56,60} 5$ weeks, ${ }^{61} 7$ months, and 13 months, ${ }^{55}$ with only a single study showing no difference between acupuncture and control at 3 months. ${ }^{6}$

\section{Bell's palsy}

Two RCTs with $480^{45}$ and $119^{59}$ subjects met the inclusion criteria (Table 2). Li et al. ${ }^{45}$ included an intermediate treatment group, "Control 1," which received both acupuncture and medical therapy, and a medical therapy "Control 2" group. Tong et al. ${ }^{59}$ included an oral steroid group "Control 1" and a home exercises "Control 2" group (Table 2). Li et al. ${ }^{45}$ found significant improvement in the House-Brackmann Scale and Facial Disability Index in the acupuncture group compared with medical therapy and of the acupuncture plus medical therapy "Control 1 " over the medical therapy "Control 2." In contrast, Tong et al. ${ }^{59}$ found no significant difference on the House-Brackmann Scale, as all three groups had high improvement rates.

\section{Acupuncture-induced changes in nerve conduction parameters}

NCS were performed in included trials on DPN and CTS (Table 4). With respect to motor nerve function, acupuncture produced significant effects on median nerve compound muscle action potential (CMAP) amplitude, median nerve distal motor latency (DML), and motor nerve conduction velocity (NCV) of the median, ulnar, and peroneal nerves. Compared with medication control, acupuncture caused significantly greater improvement in DML and in median, ulnar, and motor NCV.

Sensory NCS revealed that acupuncture caused an increase in sensory nerve action potential (SNAP) amplitude in the median nerve, lowered median nerve distal sensory latency (DSL), and increased median and peroneal nerve NCV. However, compared to medication control, acupuncture showed significant improvement only in median nerve sensory $\mathrm{NCV}^{60}$ (Table 4).

With respect to longer-term NCS changes, acupuncturetreated groups had faster sensory NCV, a trend $(p=0.07)$ toward shorter DSL ${ }^{60}$ at 4 weeks, and shorter DML and motor NCV at 13 months. ${ }^{55}$

\section{Meta-analysis on acupuncture for Bell's palsy and diabetic neuropathy}

Outcomes from all included trials on DPN and Bell's palsy were reported on the individual subject level and included in this meta-analysis. All trials used medication control. Data from Li et al.'s " 45 "Control 1" were excluded because acupuncture was administered, and from Tong et al.'s "59 "Control 2" because it was not an active control. The third arms of both trials were included in the data synthesis. A forest plot for acupuncture against control treatment was constructed using contingency tables of acupuncture

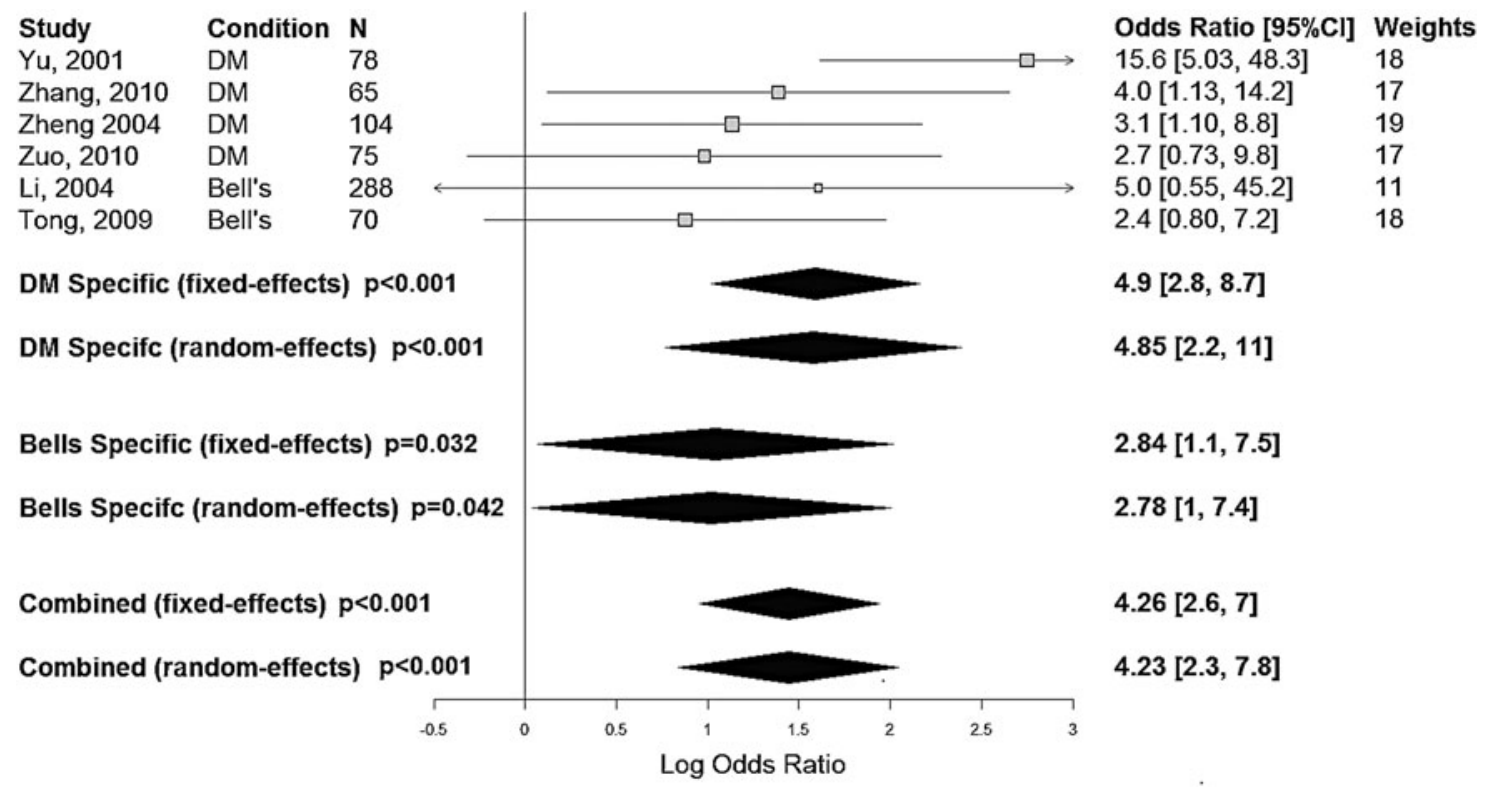

FIG. 2. Meta-analysis results for diabetes mellitus and Bell's palsy. 
against the control condition (Fig. 2). Meta-analysis on the DPN subjects showed an overall increased effect of acupuncture over control, which was still present $(p<0.001)$ when correcting for study heterogeneity (mean odds ratio $[\mathrm{OR}]=4.85$; 95\% confidence interval $[\mathrm{CI}] 2.2-11$ ). Metaanalysis on the Bell's palsy subjects also showed an increased effect of acupuncture over control $(p=0.042)$ when correcting for heterogeneity (mean $\mathrm{OR}=2.78$; $95 \%$ CI $1-$ 7.4). Similarly, the pooled meta-analysis of all trials studying diabetic neuropathy and Bell's palsy, when adjusting for study heterogeneity, found a mean OR of 4.23 in favor of acupuncture over control (95\% CI 2.3-7.8, $p<0.001)$.

\section{Acupuncture safety, adverse events}

The included studies varied greatly in how adverse events were defined and monitored. Overall acupuncture treatment appeared safe, without serious adverse events, except in the early study on HIV-related neuropathy ${ }^{58}$ where both groups experienced significant morbidity. There was a trend toward lower rates of life-threatening events in the acupuncture group (3/58 subjects) compared with the control group (10/ $56 ; p=0.06$ ), with a high combined 2-year mortality rate $(28.8 \%)$. The remaining studies reported no acupuncturerelated serious adverse events. Minor adverse events included minor bruising with acupuncture, ${ }^{56,59,65}$ which in one study was as common as $20 \%$ of subjects ${ }^{61}$; local discomfort with needle insertion; pain following session; and uncomfortable paresthesias during acupuncture in $5 \%$ of subjects. ${ }^{56}$

\section{Discussion}

To date, no critical appraisal of acupuncture's effect on PN of various etiologies has been conducted. Prior systematic reviews were published in the areas of acupuncture for DPN, CTS, and Bell's palsy. The evidence is summarized below, along with the authors' perspective.

\section{Acupuncture for DPN}

The included RCTs involved manual acupuncture ${ }^{20,63}$ or electroacupuncture, ${ }^{19}$ which were superior to control conditions in DPN, as was the combination of both therapies. ${ }^{64}$ Further studies are needed to compare acupuncture to electroacupuncture in DPN.

By far the largest number of RCTs identified in preliminary searches dealt with acupuncture for DPN. However, only four RCTs met the inclusion criteria due to poor overall quality of the reviewed studies. In 2012, Bo et al. ${ }^{67}$ attempted a systematic review and identified 75 RCTs (73 in Chinese) on acupuncture for DPN. They concluded that the majority of those were of low-moderate methodological quality, while none of the trials met all of the CONSORT ${ }^{68}$ and STRICTA ${ }^{69}$ criteria. A systematic review was thus not conducted.

In 2013, Chen et al. $^{70}$ reviewed 25 Chinese RCTs studying manual acupuncture for DPN. None of the included RCTs met all the CONSORT and STRICTA criteria, and there were no clear inclusion criteria. Meta-analysis on 23/ 25 RCTs suggested that acupuncture is more effective on a "global symptom improvement scale" than mecobalamin, vitamin $\mathrm{B} 1$ and $\mathrm{B} 12$, and no treatment. The authors identi- fied multiple methodological problems and suggested that their findings were inconclusive. Neither study included the four English language trials on DPN identified in the present study. ${ }^{19,20,63,64}$

Similar conclusions were reached in this study to those of Chen et al. ${ }^{70}$ who found acupuncture to be superior to oral thiamine plus i.m. vitamin $\mathrm{B} 12,{ }^{19}$ i.v. vitamin $\mathrm{B} 12,{ }^{20}$ oral mecobalamin, ${ }^{64}$ and oral inositol. ${ }^{63}$ Similar to the above reviews, multiple methodological problems were encountered.

\section{Acupuncture for Bell's palsy}

The same six Chinese RCTs ${ }^{71-76}$ were included in two Cochrane reviews on Bell's palsy ${ }^{77,78}$ and in a systematic review ${ }^{79}$ published by the same group. Collectively, these six RCTs suggested that acupuncture leads to improved facial nerve recovery. However, the authors warned that the conclusions cannot be trusted due to multiple methodological flaws. Tong et al. ${ }^{59}$ was not referenced. Li et al. ${ }^{45}$ was excluded from the Cochrane reviews due to use of moxibustion. Moxibustion is the stimulation caused by burning the herb Artemisia vulgaris over an acupuncture point and is widely regarded as an acupuncture modality. Trials using moxibustion were included in the present review, as long as acupuncture was also used as active intervention.

In 2012, Kim et al. ${ }^{80}$ reviewed eight RCTs, among them Tong et al., ${ }^{59}$ two studies included in the Cochrane reviews, ${ }^{72,74}$ and additional five Chinese language RCTs, ${ }^{81-85}$ all published prior to 2010, which were not included in the Cochrane 2010 review for unclear reasons. The authors excluded moxibustion, and this may be why Li et al. ${ }^{45}$ was not selected. The authors found that both acupuncture plus medication and acupuncture alone were more effective than medication alone. The authors concluded that acupuncture may be a useful adjunct or an alternative to drug therapy. However, they identified multiple methodological flaws.

The latest review on the subject included $14 \mathrm{RCTs}^{86}$-all six RCTs from the Cochrane reviews, all RCTs reviewed by Kim et al., plus two additional Chinese language RCTs. ${ }^{87,88}$ The authors did not critically assess RCT quality except for rating them "high," "low," and "unclear." Meta-analysis pooled data from 1541 individual subjects, using "effective rate" as the outcome. Acupuncture was found to be superior to control interventions (risk ratio $[\mathrm{RR}]=1.14 ; 95 \% \mathrm{CI}$ 1.04-1.25). The authors felt that their results were inconclusive due to various methodological flaws.

As the present search was limited to the English language, only two trials on manual acupuncture for Bell's palsy were included, with 599 subjects combined, which had different results. Li et al. ${ }^{45}$ found that acupuncture was more effective than a combination of acupuncture and medical therapy or medical therapy alone. Conversely, Tong et al. ${ }^{59}$ found no difference between acupuncture and the two control groups - oral steroids and home facial exercisesas all three groups had high rates of improvement from baseline. Studying episodic, self-limiting conditions such as Bell's palsy presents a challenge because the remission rate is $85 \%$ within the first 3 weeks and close to $100 \%$ within 6 months. ${ }^{89}$

Much has been written about the bias of acupuncture research coming from China. As early as 1998, Vickers et al. $^{90}$ cautioned about publishing bias and the lack of 
negative trials. While this study is almost 20 years old, there are no negative RCTs in any of the selected reviews, which raises questions about continued publication bias.

\section{Acupuncture for CTS}

The present review found that manual acupuncture ${ }^{56,60}$ and electroacupuncture ${ }^{61}$ were more effective than control in three of the four included RCTs on CTS. ${ }^{56,60,61}$ Both acupuncture and sham-acupuncture groups improved significantly in the fourth included RCT. ${ }^{62}$ A possible explanation may be that CTS has a relatively high remission rate, ranging from $33 \%$ at 6 months ${ }^{91}$ to $>50 \%$ at 1 year. $^{92}$

All four included studies on CTS involved needle placement near the median nerve. Yang et al. found this effect to be sustained at 13 months. ${ }^{55}$ Further studies are needed on acupuncture's long-term effects. Similar to the present findings, Sim et al. ${ }^{93}$ reviewed six RCTs and found acupuncture to be more effective than control in five RCTs. The authors cautioned that the selected RCTs had multiple methodological flaws and were underpowered.

\section{Acupuncture point selection}

In addition to varied acupuncture treatment courses, the included RCTs used a wide variety of acupuncture points (Table 5). Point selection rationale was not justified in any RCTs, except for one. ${ }^{63}$

There was some consistency in point selection in the treatment of CTS and Bell's palsy. All included CTS trials involved points on the ipsilateral pericardium meridian: PC6, ${ }^{56,60,62}$ PC7, ${ }^{56,60-62}$ and PC8. ${ }^{61}$ Pericardium meridian points are commonly used in CTS treatment due to their close association with the median nerve, which is affected in CTS. Similarly, both of the included Bell's palsy trials used ipsilateral points on the stomach meridian-ST2, ${ }^{59}$

Table 5. Acupuncture Point Selection

\begin{tabular}{|c|c|c|c|c|}
\hline Study & Condition & $\begin{array}{l}\text { Acupuncture } \\
\text { modality }\end{array}$ & Acupuncture point selection & $\begin{array}{l}\text { Moxibustion point } \\
\text { selection (if any) }\end{array}$ \\
\hline $\operatorname{Li} 2004^{45}$ & Bell's palsy & $\begin{array}{l}\text { Acupuncture, } \\
\text { moxibustion }\end{array}$ & $\begin{array}{l}\text { Ipsilateral: ST4, ST6, ST7, LI4, } \\
\text { GB14, SI17 } \\
\text { Bilateral: LI4 }\end{array}$ & $\begin{array}{l}\text { Hanging } \\
\text { moxibustion - } \\
5 \text { min at each point }\end{array}$ \\
\hline Tong $2009^{59}$ & Bell's palsy & Acupuncture & $\begin{array}{l}\text { Ipsilateral: ST2, ST4, ST6, EX-HN7, } \\
\text { GB14, TW17 } \\
\text { Bilateral: LI4 }\end{array}$ & $\mathrm{N} / \mathrm{A}$ \\
\hline Khosrawi $2012^{60}$ & CTS & Acupuncture & Ipsilateral: PC6, PC7 & N/A \\
\hline Kumnerddee $2010^{61}$ & CTS & Electroacupuncture & $\begin{array}{l}\text { Ipsilateral: LI4, LI11, PC7, PC8, } \\
2 \text { Ba-Xie points digits } 2 / 3 \text { and } 3 / 4\end{array}$ & N/A \\
\hline Yao $2012^{62}$ & CTS & Acupuncture & $\begin{array}{l}\text { Ipsilateral: PC6, PC7, SP6 Contralateral: } \\
\text { TW5, LI4, LI11, GB34 }\end{array}$ & $\mathrm{N} / \mathrm{A}$ \\
\hline Yang $2009^{56}$ & CTS & Acupuncture & Ipsilateral: PC6, PC7 & N/A \\
\hline Yu $2001^{19}$ & $\mathrm{DM}$ & Electroacupuncture & $\begin{array}{l}\text { Bilateral: LI4, LI11, LI15, TW5, GB30, } \\
\text { GB34, ST36, ST41, ST44 }\end{array}$ & N/A \\
\hline Zhang $2010^{63}$ & $\mathrm{DM}$ & Acupuncture & $\begin{array}{l}\text { Bilateral: BL18, BL20, BL23, BL58, } \\
\text { ST36, SP6, SP3, Yishu, ST40, GB 34; } \\
\text { Also CV6, CV4 } \\
\text { Custom points: } \\
\text { Bilateral LI4, LI10, LI11, LI15, ST31, } \\
\text { ST32, ST34, ST43, ST44, SP10, } \\
\text { BL17-for blood stasis } \\
\text { Bilateral SP8, SP9-for phlegm } \\
\text { Bilateral Bafeng and Baxie-for severe } \\
\text { numbness of the hands and feet }\end{array}$ & N/A \\
\hline Zheng $2004^{64}$ & $\mathrm{DM}$ & $\begin{array}{l}\text { Acupuncture, } \\
\text { electroacupuncture, } \\
\text { snow lotus i.m. } \\
\text { injection }\end{array}$ & $\begin{array}{l}\text { Manual acupuncture: bilateral T7Jiaji, } \\
\text { BL23, GB30; Also CV4, CV6 } \\
\text { Electroacupuncture: bilateral SP6 } \\
\text { Injection of snow lotus herb bilaterally in } \\
\text { T7 Jiaji and SP6 }\end{array}$ & N/A \\
\hline Zuo $2010^{20}$ & $\mathrm{DM}$ & Acupuncture & $\begin{array}{l}\text { Bilateral ST36, SP6, KI3, LI4, LI11, } \\
\text { TW5, CV4, and CV6 }\end{array}$ & $\mathrm{N} / \mathrm{A}$ \\
\hline Anastazi $2013^{65}$ & HIV & $\begin{array}{l}\text { Acupuncture, } \\
\text { Moxibustion }\end{array}$ & Not provided & Not provided \\
\hline Shlay $1998^{58}$ & HIV & Acupuncture & $\begin{array}{l}\text { Bilateral SP6, SP7, SP9, Ba Feng, } \\
\text { KI2, KI3 }\end{array}$ & $\mathrm{N} / \mathrm{A}$ \\
\hline Penza $2011^{66}$ & $\mathrm{DM} / \mathrm{IPN}$ & Electroacupuncture & Bilateral ST36, SP6, LR3, BL60 & N/A \\
\hline
\end{tabular}


ST4, ${ }^{45,59}$ ST6, ${ }^{45,59} \mathrm{ST} 7,{ }^{45}$ and GB $144^{45,59}$ - which are in close proximity to branches of the facial nerve. Both trials also included needling of bilateral LI4, which is one of the most commonly used points for facial pain.

The RCTs focused on acupuncture for diabetic, HIVrelated, and idiopathic neuropathy used a greater variety of acupuncture points with little overlap. This may be because these conditions cause polyneuropathy with more complex symptoms compared with mononeuropathies.

\section{Overview of statistical bias}

Statistical bias within the larger meta-analysis was evaluated using assessments of study heterogeneity $\left(I^{2}\right)$ both within each of the disease subsets and in the pooled cohort. This combined approach was utilized to evaluate any discrepancy among the studies both within and across disease states. In all cases, the heterogeneity is not significant (Bell's: $I^{2}=6 \%, p=0.55$; diabetes mellitus [DM]: $I^{2}=47 \%$, $p=0.12$; combined: $I^{2}=28 \%, p=0.22$ ), indicating the effect of acupuncture intervention is appropriately similar among the studies. Even the comparatively high $I^{2}$ value for DM is an indication of "moderate" heterogeneity according to the Cochrane criteria. ${ }^{94}$ The analysis of heterogeneity suggests that even in the absence of negative results, the effect of acupuncture treatment is moderately consistent within and across neuropathic conditions.

\section{Suggested mechanism of action}

While the selected trials employed varied acupuncture regimens, they all involved acupuncture points located near peripheral nerves, such as points close to the median nerve for CTS and close to the facial nerve for Bell's palsy (Table 5). It is possible that acupuncture needles exert direct effect on an underlying nerve and peri-neural tissues, either through manual manipulation or electric current. This could explain why acupuncture appears to have an effect not only on neuropathic symptoms, but also on NCS parameters (Table 4). These effects were sustained up to 13 months ${ }^{55}$ in CTS and were significantly different from the control condition. Further studies are needed before any definitive conclusions can be drawn about acupuncture's effect on NCS parameters in neuropathic conditions.

\section{Methodological problems with standardization}

One common problem in acupuncture research is the lack of standardization of point selection, number of needles used, needle retention time, needling depth, needle manipulation, use of moxibustion, and electroacupuncture. The 13 RCTs reviewed varied greatly in acupuncture point selection and in number of sessions: from six weekly sessions for DPN $^{62}$ to 36 sessions in Bell's palsy. ${ }^{59}$ Consideration was given to calculating the amount of acupuncture delivered (in minutes or hours). However, there is no clear concept of an appropriate acupuncture dose and how much treatment is needed for a given condition. ${ }^{95}$ The relationship between number of needles and acupuncture effect is also unclear and probably not linear.

Lastly, isolating acupuncture's effect would be simpler in RCTs that study acupuncture alone as the intervention. Half of the included RCTs combined acupuncture with another in- tervention-moxibustion, medication or herbs, or splinting. This is further complicated by the use of various acupuncture modalities-manual acupuncture, , $^{20,45,56,58-60,62,63,65}$ electroacupuncture, ${ }^{19,61,66}$ or a combination of both. ${ }^{64}$ Manual and electroacupuncture may have different mechanisms of action and different effects on neuropathy and neuropathic pain. Unfortunately, not enough electroacupuncture trials were available to draw meaningful comparisons with manual acupuncture for each of the reviewed neuropathic conditions.

\section{Methodological problems with sample size calculations}

Only two of the included RCTs ${ }^{58,65}$ contained a sample size calculation. Therefore, it is possible that the majority of the included trials are underpowered (Table 6). In particular Penza et al. ${ }^{66}$ only enrolled eight subjects per group, and only 12 subjects had idiopathic neuropathy. There was no statistical rationalization for this sample size and this uneven split of patients with idiopathic and diabetic neuropathy.

\section{Methodological problems with improper control and blinding}

In Traditional Chinese Medicine, there is a belief that a sensation called de qi is crucial to acupuncture's therapeutic benefit. De qi has been described as aching, soreness, heaviness, warmth, coolness, tingling, numbness at the site of the needle, ${ }^{96}$ or as radiating paresthesias. ${ }^{97}$ Because of this belief, many RCTs from China are designed to compare de $q i$ elicited by needle manipulation to manipulation-free needling of an acupuncture point. ${ }^{39,40}$ Any studies that involved passive needle insertion in acupuncture point as control were excluded.

Lack of blinding of both subjects and investigators was a common methodological flaw of the selected studies. None of the studies originating in China ${ }^{19,20,45,56,59,63,64}$ used sham acupuncture, and the subjects were not blinded (Table 6). In 7 of the 13 included studies, ${ }^{19,20,45,56,59,63,64}$ the outcome assessors were not blinded to treatment assignment, which is source of investigator bias.

\section{Methodological problems with placebo and expectancy}

Most of the included RCTs carried out a greater number of visits or interventions in the acupuncture groups (Table 2), which may have affected subject expectancy. In many cases, the authors alluded to positive subject expectations from acupuncture, including higher dropout rates in the control condition and subjects seeking acupuncture independently. ${ }^{56,59}$ Subject expectations and the role of placebo in general were not addressed. It is well known that positive expectation amplifies acupuncture-induced analgesia in both subjective pain ratings and objective fMRI signal changes. ${ }^{98}$

\section{Methodological problems with outcome measures}

The 13 included RCTs contained a wide array of outcome measures, as should be expected with trials on various neuropathic conditions, involving both poly- and mononeuropathy. Overall, most trials assessed subject-reported measures of improvement, which are intrinsically subjective. Only four of the 13 RCTs used NCS for baseline and outcome measures (Table 4). More studies of neuropathy 


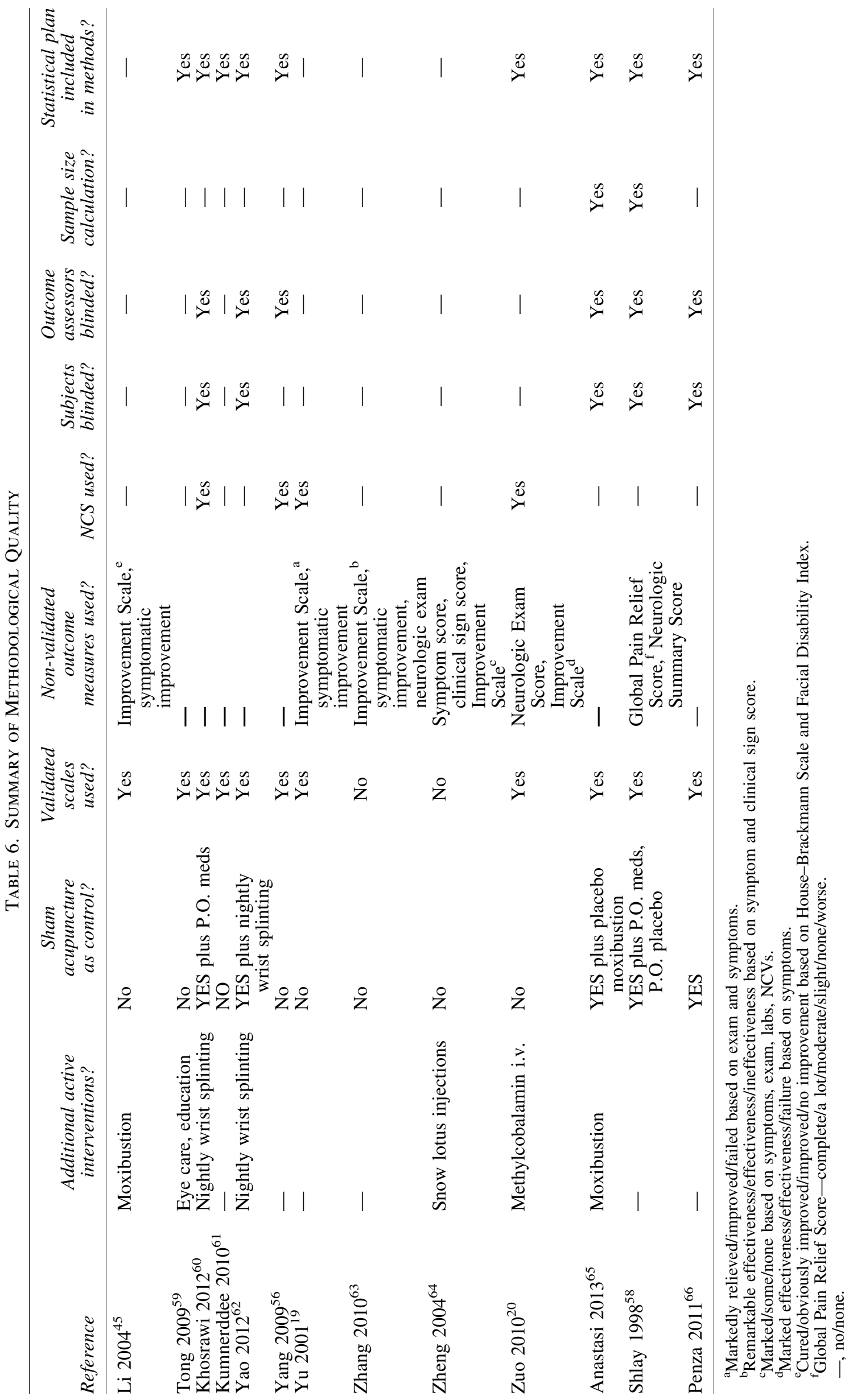


should use NCS or other objective measures of improvement such as somatosensory evoked potentials.

Several included studies used arbitrary, investigatorcreated scales of improvement (Table 6), such as "complete/ a lot/moderate/slight/none/worse," of symptoms, neurologic exam, and improvement on diseasespecific, validated scales. These could be a significant source of bias, particularly if the outcome assessors are not blinded to treatment assignment. With the exception of Zhang et al., ${ }^{63}$ all RCTs using investigator-created scales of improvement also used validated outcome measures.

\section{Conclusions}

This systematic review suggests that acupuncture is effective in diabetic neuropathy, Bell's palsy, and CTS, under the conditions of the included studies. Acupuncture may be effective in HIV-related neuropathy. However, further studies are needed to explore its potential therapeutic role in this population. There is a need for future studies that address point selection, acupuncture modality, and frequency. Further studies should also aim to minimize methodological flaws by incorporating proper subject and investigator blinding, standardization of acupuncture intervention, use of validated, objective outcome assessments, a priori hypotheses with proper sample and effect size calculations, and appropriate statistical analyses.

\section{Acknowledgments}

This study is funded by the following grants: NIH K23 AT008405 (A.D.), NIH 5T32 AT002688 (B.O.). The authors wish to thank Prof. Marian McDonagh, PharmD, from OHSU's department of Medical Informatics and Clinical Epidemiology for her contribution to this manuscript.

\section{Author Disclosure Statement}

No competing financial interests exist.

\section{References}

1. Diehl DL, Kaplan G, Coulter I, et al. Use of acupuncture by American physicians. J Altern Complement Med 1997;3:119126.

2. Eisenberg DM, Kessler RC, Foster C, et al. Unconventional medicine in the United States. Prevalence, costs, and patterns of use. N Engl J Med 1993;328:246-252.

3. NIH Consensus Conference. Acupuncture. JAMA 1998; 280:1518-1524.

4. Manheimer E, White A, Berman B, et al. Meta-analysis: Acupuncture for low back pain. Ann Intern Med 2005;142: 651-663.

5. Furlan AD, van Tulder M, Cherkin D, et al. Acupuncture and dry-needling for low back pain: An updated systematic review within the framework of the cochrane collaboration. Spine (Phila Pa 1976) 2005;30:944-963.

6. Linde K, Allais G, Brinkhaus B, et al. Acupuncture for migraine prophylaxis. Cochrane Database Syst Rev 2009; CD001218.

7. Linde K, Allais G, Brinkhaus B, et al. Acupuncture for tension-type headache. Cochrane Database Syst Rev 2009; CD007587.
8. Ezzo JM, Richardson MA, Vickers A, et al. Acupuncturepoint stimulation for chemotherapy-induced nausea or vomiting. Cochrane Database Syst Rev 2006;CD002285.

9. Vickers AJ, Cronin AM, Maschino AC, et al. Acupuncture for chronic pain: Individual patient data meta-analysis. Arch Intern Med 2012;172:1444-1453.

10. Amato AA, Russell JA. Neuromuscular Disorders. New York: McGraw-Hill Medical, 2008.

11. Herskovitz S, Scelsa SN, Schaumburg HH. Peripheral Neuropathies in Clinical Practice. New York: Oxford University Press, 2010.

12. Gordon Smith A, Robinson Singleton J. Idiopathic neuropathy, prediabetes and the metabolic syndrome. J Neurol Sci 2006;242:9-14.

13. Martyn CN, Hughes RA. Epidemiology of peripheral neuropathy. J Neurol Neurosurg Psychiatry 1997;62:310-318.

14. Chong MS, Bajwa ZH. Diagnosis and treatment of neuropathic pain. J Pain Symptom Manage 2003;25:S4-S11.

15. Vincent A, Kruk KM, Cha SS, et al. Utilisation of acupuncture at an academic medical centre. Acupunct Med 2010;28:189-190.

16. Barnes PM, Bloom B, Nahin RL; National Center for Health Statistics (U.S.). Complementary and Alternative Medicine Use Among Adults and Children: United States, 2007. Hyattsville, MD: Department of Health and Human Services, Centers for Disease Control and Prevention, National Center for Health Statistics, 2008.

17. Jeste DV, Dunn LB, Folsom DP, et al. Multimedia educational aids for improving consumer knowledge about illness management and treatment decisions: A review of randomized controlled trials. J Psychiatr Res 2008;42:1-21.

18. D'Silva S, Poscablo C, Habousha R, et al. Mind-body medicine therapies for a range of depression severity: A systematic review. Psychosomatics 2012;53:407-423.

19. Yu J, Cui Z. Clinical study of diabetic peripheral neuropathy treated by acupuncture. Int J Clin Acupunct 2001;12: $315-318$.

20. Zuo L, Zhang L. Study on the effect of acupuncture plus methylcobalamin in treating diabetic peripheral neuropathy. J Acu Tuina Sci 2010;8:249-252.

21. R-Core Team. R: A language and environment for statistical computing. Vienna, Austria: R Foundation for Statistical Computing,; 2013. Online document at: www .R-project.org/, accessed November 3, 2016.

22. Lumley T. rmeta: Meta-analysis. R package version 2.16. Online document at: http://cran.r-project.org/web/packages/ rmeta/rmeta.pdf, accessed November 3, 2016.

23. Li Z. Mingmu dihuang tang combined with electroacupuncture for treatment of diabetic oculomotor paralysis in 52 cases. J Tradit Chin Med 2007;27:37-38.

24. Man PL. Acupuncture analgesia for the treatment of trigeminal neuralgias: A series of forty-one cases. J Natl Med Assoc 1975;67:115-117.

25. Hu J. Acupuncture treatment of herpes zoster. J Tradit Chin Med 2001;21:78-80.

26. Abuaisha BB, Costanzi JB, Boulton AJ. Acupuncture for the treatment of chronic painful peripheral diabetic neuropathy: A long-term study. Diabetes Res Clin Pract 1998;39:115-121.

27. Green J, McClennon J. Acupuncture: An effective treatment for painful diabetic neuropathy. Diabet Foot J 2006; 9(4):182-191.

28. Donald GK, Tobin I, Stringer J. Evaluation of acupuncture in the management of chemotherapy-induced peripheral neuropathy. Acupunct Med 2011;29:230-233. 
29. Lee S, Kim JH, Shin KM, et al. Electroacupuncture to treat painful diabetic neuropathy: Study protocol for a threearmed, randomized, controlled pilot trial. Trials 2013;14:225.

30. Galantino ML, Eke-Okoro ST, Findley TW, et al. Use of noninvasive electroacupuncture for the treatment of HIVrelated peripheral neuropathy: A pilot study. J Altern Complement Med 1999;5:135-142.

31. Yongping J, Stefanovic J. The acupuncture treatment of peripheral neuropathy in HIV/AIDS. J Chin Med 2002; 27-29.

32. $\mathrm{Lu} \mathrm{Z}$, Chen Z. Electroacupuncture for treatment of 12 cases of infantile peroneal nerve injury. J Tradit Chin Med 2000; 20:130-131.

33. Branco K, Naeser MA. Carpal tunnel syndrome: Clinical outcome after low-level laser acupuncture, microamps transcutaneous electrical nerve stimulation, and other alternative therapies - an open protocol study. J Altern Complement Med 1999;5:5-26.

34. Zhou Y, Garcia MK, Chang DZ, et al. Multiple myeloma, painful neuropathy, acupuncture? Am J Clin Oncol 2009; 32:319-325.

35. Phillips KD, Skelton WD, Hand GA. Effect of acupuncture administered in a group setting on pain and subjective peripheral neuropathy in persons with human immunodeficiency virus disease. J Altern Complement Med 2004;10:449-455.

36. Schroder S, Liepert J, Remppis A, et al. Acupuncture treatment improves nerve conduction in peripheral neuropathy. Eur J Neurol 2007;14:276-281.

37. Schroeder S, Meyer-Hamme G, Epplee S. Acupuncture for chemotherapy-induced peripheral neuropathy (CIPN): A pilot study using neurography. Acupunct Med 2012;30:4-7.

38. Xie Z. 51 cases of occipital neuralgia treated with acupuncture. J Tradit Chin Med 1992;12:180-181.

39. Tong Y, Guo H, Han B. Fifteen-day acupuncture treatment relieves diabetic peripheral neuropathy. J Acupunct Meridian Stud 2010;3:95-103.

40. Xu SB, Huang B, Zhang CY, et al. Effectiveness of strengthened stimulation during acupuncture for the treatment of Bell palsy: A randomized controlled trial. CMAJ 2013;185:473-479.

41. Napadow V, Liu J, Li M, et al. Somatosensory cortical plasticity in carpal tunnel syndrome treated by acupuncture. Hum Brain Mapp 2007;28:159-171.

42. Lun X. Treatment of diabetic peripheral neuropathy using Chinese herbs and acupuncture. Int J Clin Acupunct 1995; 6:271-273.

43. Hui F, Boyle E, Vayda E, et al. A randomized controlled trial of a multifaceted integrated complementary-alternative therapy for chronic herpes zoster-related pain. Altern Med Rev 2012;17:57-68.

44. Liang F, Li Y, Yu S, et al. A multicentral randomized control study on clinical acupuncture treatment of Bell's palsy. J Tradit Chin Med 2006;26:307.

45. Li Y, Liang FR, Yu SG, et al. Efficacy of acupuncture and moxibustion in treating Bell's palsy: A multicenter randomized controlled trial in China. Chin Med J (Engl) 2004; 117:1502-1506.

46. Ahn AC, Bennani T, Freeman R, et al. Two styles of acupuncture for treating painful diabetic neuropathy-a pilot randomised control trial. Acupunct Med 2007;25:11-17.

47. Ursini T, Tontodonati M, Manzoli L, et al. Acupuncture for the treatment of severe acute pain in herpes zoster: Results of a nested, open-label, randomized trial in the VZV Pain Study. BMC Complement Altern Med 2011;11:46.
48. Lewith GT, Field J, Machin D. Acupuncture compared with placebo in post-herpetic pain. Pain 1983;17:361-368.

49. Cai DF. Warm-needling plus Tuina relaxing for the treatment of carpal tunnel syndrome. J Tradit Chin Med 2010; 30:23-24.

50. Danciu A, Danciu E. The preference of acupuncture treatment in autonomic diabetic neuropathy. Am J Acupunct 1985;13:247-252.

51. Jiang H, Shi K, Li X, et al. Clinical study on the wrist-ankle acupuncture treatment for 30 cases of diabetic peripheral neuritis. J Tradit Chin Med 2006;26:8-12.

52. Naeser MA, Hahn KA, Lieberman BE, et al. Carpal tunnel syndrome pain treated with low-level laser and microamperes transcutaneous electric nerve stimulation: A controlled study. Arch Phys Med Rehabil 2002;83:978-988.

53. Qian W, Qian H, Wu T, et al. Clinical research on acupuncture treatment of diabetic peripheral neuropathy. J Acu Tuina Sci 2004;2:12-14.

54. Shao L. Observations on the curative effect of acupuncture on cardiac vegetative neuropathy of diabetes. J Acu Tuina Sci 2004;2:18-20.

55. Yang CP, Wang NH, Li TC, et al. A randomized clinical trial of acupuncture versus oral steroids for carpal tunnel syndrome: A long-term follow-up. J Pain 2011;12:272279.

56. Yang CP, Hsieh CL, Wang NH, et al. Acupuncture in patients with carpal tunnel syndrome: A randomized controlled trial. Clin J Pain 2009;25:327-333.

57. Shiflett SC, Schwartz GE. Effects of acupuncture in reducing attrition and mortality in HIV-infected men with peripheral neuropathy. Explore (NY) 2011;7:148-154.

58. Shlay JC, Chaloner K, Max MB, et al. Acupuncture and amitriptyline for pain due to HIV-related peripheral neuropathy: A randomized controlled trial. Terry Beirn Community Programs for Clinical Research on AIDS. JAMA 1998;280:1590-1595.

59. Tong FM, Chow SK, Chan PY, et al. A prospective randomised controlled study on efficacies of acupuncture and steroid in treatment of idiopathic peripheral facial paralysis. Acupunct Med 2009;27:169-173.

60. Khosrawi S, Moghtaderi A, Haghighat S. Acupuncture in treatment of carpal tunnel syndrome: A randomized controlled trial study. J Res Med Sci 2012;17:1-7.

61. Kumnerddee W, Kaewtong A. Efficacy of acupuncture versus night splinting for carpal tunnel syndrome: A randomized clinical trial. J Med Assoc Thai 2010;93:14631469.

62. Yao E, Gerritz PK, Henricson E, et al. Randomized controlled trial comparing acupuncture with placebo acupuncture for the treatment of carpal tunnel syndrome. PM R 2012;4:367-373.

63. Zhang C, Ma YX, Yan Y. Clinical effects of acupuncture for diabetic peripheral neuropathy. J Tradit Chin Med 2010; 30:13-14.

64. Zheng HT, Li YF, Yuan SX. Observations on 52 patients with diabetic peripheral neuropathy treated by needling combined with drug. J Acu Tuina Sci 2004;2:24-26.

65. Anastasi JK, Capili B, McMahon DJ, et al. Acu/Moxa for distal sensory peripheral neuropathy in HIV: A randomized control pilot study. J Assoc Nurses AIDS Care 2013;24: 268-275.

66. Penza P, Bricchi M, Scola A, et al. Electroacupuncture is not effective in chronic painful neuropathies. Pain Med 2011;12:1819-1823. 
67. Bo C, Xue Z, Yi G, et al. Assessing the quality of reports about randomized controlled trials of acupuncture treatment on diabetic peripheral neuropathy. PLoS One 2012; 7:e38461.

68. Schulz KF, Altman DG, Moher D. CONSORT 2010 statement: Updated guidelines for reporting parallel group randomised trials. BMJ 2010;340:c332.

69. MacPherson H, Altman D, Hammerschlag R, et al. Revised STandards for Reporting Interventions in Clinical Trials of Acupuncture (STRICTA): Extending the CONSORT statement. PLoS Med 2010;7:e1000261.

70. Chen W, Yang GY, Liu B, et al. Manual acupuncture for treatment of diabetic peripheral neuropathy: A systematic review of randomized controlled trials. PLOS ONE 2013; 8:e73764.

71. Li J. Comparison the efficacy between acupuncture and manipulation for Bell's palsy. Chin Clin Med Res 2005;11: 1715-1716.

72. Liu M. Comparison of acupuncture and drug treatment for 130 patients with facial palsy. J Clin Acupunct 1996; 12:56.

73. Ma Z. Clinical Observations on acupuncture and moxibustion treatment of HIV positive peripheral facial paralysis. Shanghai J of Acupunct Moxib 2004;23:19-20.

74. Shao S. Acupuncture and western medicine for 58 patients with peripheral facial palsy. New Chin Med 1999; 30:14.

75. Yang G. Comparison of the efficacy between acupuncture and therapy apparatus for Bell's palsy. J Clin Acupunct Moxib 2001;17:28-29.

76. Yu Y. Analysis of acupuncture for peripheral facial palsy. Shanghai J Acupunct Moxib 1999;18:26.

77. He L, Zhou MK, Zhou D, et al. Acupuncture for Bell's palsy. Cochrane Database Syst Rev 2007;CD002914.

78. Chen N, Zhou M, He L, et al. Acupuncture for Bell's palsy. Cochrane Database Syst Rev 2010;CD002914.

79. Zheng H, Li Y, Chen M. Evidence based acupuncture practice recommendations for peripheral facial paralysis. Am J Chin Med 2009;37:35-43.

80. Kim JI, Lee MS, Choi TY, et al. Acupuncture for Bell's palsy: A systematic review and meta-analysis. Chin J Integr Med 2012;18:48-55.

81. Dai F, Zhang Y. Acupuncture point-penetrating method combined with glucocorticoids for 36 cases of Bell's palsy. Zhejiang J Tradit Chin Med 2009;44.

82. Wang L. Clinical observation on acupuncture combined medicine treatment for acute idiopathic facial paralysis. J Sichuan Tradit Chin Med 2007;25:109-110.

83. Xuan L, Wang L, Hou J, et al. Study on shendao point of wild-horizontal needling for functional recovery of facial paralysis of facial muscles. Chin J Tradit Med Sci Technol 2007; 14:6-7.

84. Yang C, Bao J, Zhang Z, et al. Observations on the efficacy of combined acupuncture and medication for treating in 320 cases of facial paralysis. Sci Tech Info Gansu 2006; 35:240-241.
85. Zhu L. Observations on the efficacy of combined acupuncture and medication for treating the acute stage of peripheral facial paralysis. Shanghai J Acupunct Moxibust 2006;25:17-18.

86. Li P, Qiu T, Qin C. Efficacy of acupuncture for Bell's palsy: A systematic review and meta-analysis of randomized controlled trials. PLoS One 2015;10:e0121880.

87. Zhao Y, He L, Zhang Q. Effectiveness of three different treatments for peripheral facial paralysis. Chin J Clin Rehab 2005;29 41-43.

88. Zhu H, Jiang J, Feng L, et al. Intractable facial paralysis treated with stellate ganglion block plus electric acupuncture. Chin J Pain Med 2004;5:263.

89. Peitersen E. The natural history of Bell's palsy. Am J Otol 1982;4:107-111.

90. Vickers A, Goyal N, Harland R, et al. Do certain countries produce only positive results? A systematic review of controlled trials. Controlled Clin Trials 1998;19:159-166.

91. Futami T, Kobayashi A, Ukita T, et al. Carpal tunnel syndrome; its natural history. Hand Surg 1997;2:129-130.

92. Silverstein BA, Fan ZJ, Bonauto DK, et al. The natural course of carpal tunnel syndrome in a working population. Scand J Work Environ Health 2010;36:384-393.

93. Sim H, Shin BC, Lee MS, et al. Acupuncture for carpal tunnel syndrome: A systematic review of randomized controlled trials. J Pain 2011;12:307-314.

94. Higgins JPT, Green S, eds. Cochrane Handbook for Systematic Reviews of Interventions. Version 5.1.0 [updated March 2011]. The Cochrane Collaboration, 2011. Online document at: www.handbook.cochrane.org, accessed November 3, 2016.

95. White A, Cummings M, Barlas P, et al. Defining an adequate dose of acupuncture using a neurophysiological approach-A narrative review of the literature. Acupunct Med 2008;26:111-120.

96. Hui KK, Nixon EE, Vangel MG, et al. Characterization of the "deqi" response in acupuncture. BMC Complement Altern Med 2007;7:33.

97. Kou W, Gareus I, Bell JD, et al. Quantification of DeQi sensation by visual analog scales in healthy humans after immunostimulating acupuncture treatment. Am J Chin Med 2007;35:753-765.

98. Kong J, Kaptchuk TJ, Polich G, et al. An fMRI study on the interaction and dissociation between expectation of pain relief and acupuncture treatment. Neuroimage 2009; 47:1066-1076.

Address correspondence to: Alexandra Dimitrova, $M D$ Department of Neurology Oregon Health and Science University 3181 SW Sam Jackson Park Road Mail Code CR120 Portland, OR 97239

E-mail:dimitroa@ohsu.edu 